60

\title{
Why bad things happen to
}

\section{good systems}

\author{
Lawrence BERNSTEIN, Technologist, Price Waterhouse, \\ Chief Technologist, Network Programs, Inc., \\ Executive Director, Bell Labs (ret.), U.S.A.
}

Network Management Systems are generally in the class of high performance on-line systems. With the TMN standard finally being taken seriously they are becoming part of the network elements themselves and becoming real-time systems. But they are still software systems.

Software systems suffer from a reputation of being buggy. Sometimes they are. In other cases, the customer buys a system and immediately insists on having it changed. This can and usually does introduce bugs.

Before customers buy a system, their interest is in features, price and schedule. Once they get it, their attention turns to reliability, response time and throughput. It is the job of the supplier to make sure that all six areas are considered at the time of purchase and managed throughout the entire system life cycle.

In one real life situation, a customer bought an 'off-the-shelf,' working product and refused to buy a critical module. After an initial test at the suppliers shop, the customer asked for 33 enhancements. One of these required a $20 \%$ change of the system. The developers were too optimistic about their ability to make the requested changes, and so the 'law of unintended consequences' frustrated the users and kept the developers working late into the night.

In this case, the customer lost patience, tossed out the network management system and all parties had their day in court - too many days. With good project and program management, common goals, patience and realistic expectations, this story could have had a happy ending. 